\title{
Perceptions of Teachers on the Promotion of Women into Leadership Positions in the Ministry of Education in Eswatini: The Case of Manzini Region
}

\author{
Wilard Nyathi* \\ AMADI University, Eswatini, Zimbabwe
}

*Corresponding Author: Wilard Nyathi, AMADI University, Eswatini, Zimbabwe

\begin{abstract}
This study sought to investigate the feelings of secondary school teachers towards the promotion of women into leadership positions in the ESwatini Region of Manzini. A total of 300 respondents were used of which 53\% were male and $47 \%$ were female. The research instrument used was the questionnaire which had both close-ended and open-ended questions. Descriptive statistical analysis was used to interpret the data. The study revealed that the majority of male teachers have negative attitudes towards female education leaders. More female teachers support their fellow females in administration. The study recommends that the Government should promote women on merit so that they may be respected by their workmates. All administrators in promotion should attend in-service workshops to up-date them on current leadership trends. Teachers, particularly the male ones should be sensitised on gender equality in order to change their negative attitudes towards female leaders.
\end{abstract}

Keywords: Perceptions, teachers, secondary school, leadership, promotion, district

\section{INTRODUCTION}

The issue of women in leadership and management positions has been a matter of concern worldwide. This is because it had a negative impact on female capabilities with regards to their leadership and management in schools. In many countries including ESwatini, women were regarded as people who cannot lead and manage schools as men can do (Blount, 1998; Mosetse, 2006; Kiamba, 2008). That is, leadership role was basically associated with males, while, women were only considered fit to do mainly the actual teaching duties in the classrooms. Leadership and management responsibilities were associated with intelligence and power which, some people thought, are found in men rather than in women. However, in the context of ESwatini, there are well known barriers which have exacerbated an already existing situation that keeps women out of management positions, and they are still continuing. Consequently, among the factors that contributed to the gender gap, are education and culture in the sense that formal education, which was taught to women, limited their access to, and achievement of management positions. For example, women were exposed to subjects like homeeconomics and business studies which were just preparing them to become good mothers as well as good teachers (Task Force Report, 1982; Eprech, 1992; Molapo, 2005). Secondly, Lesotho, being a patriarchal country, promotes patriarchal patterns and gender discrimination which marginalises women from leadership positions. Their practices and beliefs that were passed on to elders were also passed on in the professional institutions like schools In the past, prior to 1966 in ESwatini, education was provided by the missionaries. Employment and payment of teachers" salaries as well as, the provision of school facilities were their responsibilities. During those times, only males were considered to be principals of both primary and secondary schools. There has never been a formal entry qualification for principal ship. 2 Principals were appointed on the basis of their successful record as teachers (Bush \& Oduro, 2006). But due to patterns of male dominance which influences unequal power relations that exists between men and women, male principals were appointed instead of female candidates who qualified. Women were not given equal opportunity to employment and promotion into leadership position. Hence they were employed in terms and conditions of temporary job and they were non-pensionable because of their reproductive roles (Kimane, Ntimo-Makara \& Mapetla, 1992). 
Perceptions of Teachers on the Promotion of Women into Leadership Positions in the Ministry of Education in Eswatini: the Case of Manzini Region

\section{REVIEW OF RELATED LiteratURE}

According to Ozigi (2004), sex roles, stereotyping and career mapping of women emerge as strong barriers to female advancement into positions which have traditionally been associated with men, particularly management positions. In most African countries the education system tended to reinforce the traditional division of roles between males and females (Evetts, 2009). The traditional society tended to exclude most girls from achieving literacy in preference to boys (Chivore, 2005). According to current statistics in ESwatini, few females are school principals (Madziyire, 2005). In Zimbabwe, for example, before 1986, women had to resign from the permanent teacher pay roll upon marriage and were therefore not legible for promotion to leadership positions (Chivore, 2005).

As Smyth (2012) argues, if women act according to the male definition of a leader (being aggressive, achievement oriented, self confident, forceful or competitive) she is condemned as being unfeminine. Therefore, women leadership has been poorly represented in organisations (including schools) because of the criticism of feminine leadership in organisations (Luke and Gore, 2012). According to Shakeshalf (2006) the most important factor affecting achievement of women is not the external environment (poverty or other handicaps) but it is the inner environment, the self-image and the other handicaps, the level of aspirations which is the root cause of motivation. This self-image subtlety moulded by society has been and still is inimical to the full development of whatever creativity women possess (Johnson, 2010).

There also existed a gender division of labour in organisations which historically defined women positions in a negative manner (Best, 2013). Organizational leadership theories neglected the significance of gender and only discussed authority, power and division of labour in organisations as being essential and neutral. As Johnson (2010) argues to lead is to be at the centre of the group rather than in front of others and leadership therefore is seen as the ability to act with others to do things that would not be done by an individual, which means that a leader can either be male or female.

On the other hand, some authorities have strong sentiments against the promotion of women in administrative positions. For example, Rammer and Davies (2008) advocate for the victim model which places the blame on women themselves. The model highlights the reasons for not considering women for promotion include that they are less likely to be committed to their work, they are likely to get married and so will stop or at least postpone their career even as professionals, their main responsibility is to their homes, husband and family and that these will always come first in their thinking (Rammer and Davies, 2008). Women cannot handle responsibility because they are not natural leaders; they lack confidence in work related competition (Rammer and Davies, 2008).

According to Robbins (2011), marital status has no effect at all on productivity; instead, he argued that married women had fewer absences and were more satisfied with their jobs than their unmarried co-workers and marriage appeared to impose responsibilities that made a steady job more valuable and important. Gillian (2012) states that women are reported as achieving administrative positions at a later stage than man.

According to Al-Khalifa (2008) women were more effective in their leadership roles than men, and leadership skills were not biologically rooted or genetically determined but rather shaped, facilitated or stunted by some social forces and the entire process of socialization. Men tended to be exploitative and oriented towards adopting winner take-all strategies and acted very openly in ways that limit the chances of participants in achieving success. In another study, Best (2009) found no consistent malefemale differences in problem-solving, ability, analytical skills, competitiveness, drive, motivation, sociability or learning ability. Robbins (2011) found that women adopted a more democratic leadership style, they encouraged participation, shared power and information and enhanced followers' self worth. Women were noted to lead through inclusion and relied on their charism, expertise, contacts and interpersonal skills to influence equal access to education and leadership (Davies, 2012).

While men were found to be more likely to use a directive command and control style, women leaders emphasised care for subordinates, co-operation and interdependence (Robbins, 2011). According to Best (2013), women as a social group learned or were taught to value affiliation or relationship with others rather than to desire power over them. Synth (2012) also argued in favour of female leadership and pointed out that women leaders were not so afraid of success and they were more prepared than their male counterparts to admit to the negative or the other side of competition. 


\subsection{Statement of The Problem}

The number of women teachers in administrative positions in ESwatini schools is very low considering that women constitute more than half the teacher population in the country. Various affirmative strategies have been put in place and yet the situation does not seem to improve. There is need therefore to find out what exactly teachers' views regarding the promotion of women into leadership positions.

\subsection{Purpose of the Study}

The study seeks to explore teachers' views towards promotion of women in leadership positions.

\subsection{Research Questions}

The study sought to provide answers to the following research questions:

1. Do teachers view women leaders as competent or not?

2. How does culture influence the perceptions of teachers towards women leaders?

3. How do male leaders view female leaders?

4. Are women themselves prepared to take leadership positions?

\subsection{Significance of the Study}

It was hoped that the research would be used by the Ministry of Education to encourage more women to take up leadership positions in various capacities in the education sector. The research also hopes to expose the real feelings of teachers in the schools so that strategies may be crafted to promote positive attitudes of teachers towards female leaders.

\subsection{Limitations of the Study}

In view of the small size of sample and sub-samples, the findings of this study therefore will have limited generalizability. It has to be pointed out that attitudes about an issue are essentially subjective and cannot be measured accurately. In other words, attitudes have no universally recognized and accepted scales of measurement, and measures that were used in this study cannot be considered to be absolutely accurate.

\subsection{Delimitation}

The study was confined to Manzini Region of ESwatini using a sample of 300 respondents made up of 53\% female and $47 \%$ male. It was concerned with teachers' perceptions towards the promotion of women into leadership positions in the Ministry of Primary and Secondary Education. The respondents were teachers and heads. Other key stakeholders like education officers, directors, parents as well as community leaders were outside the purview of this study.

\section{RESEARCH METHODOLOGY}

The quantitative methodology was used. The quantitative methodology was found useful in this study because it enabled the researcher to investigate 300 teachers' perceptions on the phenomenon of women in leadership positions. The survey research design was used because it enables the researchers to gather wide spread perceptions of respondents in regards to studied phenomena (Lawson and Lovell, 2010). The questionnaire with close-ended questions was used to collect predetermined respondents' opinions regarding the studied phenomenon (Cohen and Manion, 2009). The researcher personally distributed the questionnaires to the selected respondents at the schools after being granted permission by the school authorities. The questionnaires were also collected by the researcher to maximize on returns. The questionnaire produced descriptive statistics around the variables under study.

\subsection{Findings and Discussion}

\subsubsection{Presentation of data}

Table1. Distribution of respondents by sex $(N=300)$

\begin{tabular}{|l|l|l|}
\hline Category of respondents & Frequency & Percentage \\
\hline Male & 140 & 47 \\
Female & 160 & 53 \\
\hline Total & $\mathbf{3 0 0}$ & $\mathbf{1 0 0}$ \\
\hline
\end{tabular}


Perceptions of Teachers on the Promotion of Women into Leadership Positions in the Ministry of Education in Eswatini: the Case of Manzini Region

The majority of the respondents as shown in table 1 above were female (53\%) and males constituted 47\%. This observation tallies with statistics from the Zimstat figures which state that female teachers make up 52\% of the teaching force in Zimbabwe (Makoni, 2009).

Table2. Composition of respondents by teaching experience $(N=300)$

\begin{tabular}{|l|l|l|}
\hline Teaching experience & Frequency & Percentage \\
\hline $1-5$ & 94 & 31 \\
$6-10$ & 144 & 48 \\
$11-15$ & 44 & 15 \\
20 and above & 18 & 6 \\
\hline Total & $\mathbf{3 0 0}$ & $\mathbf{1 0 0}$ \\
\hline
\end{tabular}

A large number of respondents (48\%) had $6-10$ years of teaching experience, followed by the $1-5$ years teaching experience (31\%). Those who had $11-15$ years of experience constituted 155 and only $6 \%$ had been in the system for 20 years and above.

Table3. Do you support the promotion of female teachers $(N=300)$

\begin{tabular}{|l|l|l|l|l|l|l|}
\hline Category of responses & \multicolumn{3}{|l|}{ Male } & Female & Totals \\
\hline & F & \% & F & \% & F & $\%$ \\
\hline Strongly Agree & 8 & 6 & 92 & 58 & 100 & 33 \\
Agree & 4 & 3 & 18 & 11 & 22 & 7 \\
Disagree & 30 & 21 & 36 & 23 & 66 & 23 \\
Strongly Disagree & 86 & 61 & 4 & 2 & 90 & 30 \\
Not sure & 12 & 9 & 10 & 6 & 22 & 7 \\
\hline Total & $\mathbf{1 4 0}$ & $\mathbf{1 0 0}$ & $\mathbf{1 6 0}$ & $\mathbf{1 0 0}$ & $\mathbf{3 0 0}$ & $\mathbf{1 0 0}$ \\
\hline
\end{tabular}

The information above reveals that there is a discrepancy in the responses from males and females regarding this phenomenon. Whereas $69 \%$ female respondents indicated that they supported the promotion of women teachers, a significant $82 \%$ of the male respondents did not support the idea. A sizeable number of female respondents $(25 \%)$ also joined their male counterparts who stated that they did not support the promotion of female teachers. On the whole, 53\% of the respondents did not support the promotion of women teachers into leadership positions and $40 \%$ were supportive of the idea.

Table4. Responses to the question "Which of these promotion posts should be reserved for female teachers" $(N=300)$

\begin{tabular}{|l|l|l|l|l|l|l|}
\hline Category of responses & Male & Female & \multicolumn{2}{l|}{ Totals } \\
\hline & F & \% & F & \% & F & \% \\
\hline District Education Officer & 4 & 3 & 8 & 10 & 10 & 7 \\
Head of School & 8 & 6 & 13 & 16 & 17 & 21 \\
Deputy head & 32 & 23 & 28 & 35 & 44 & 29 \\
Teacher-in-charge & 96 & 68 & 31 & 39 & 79 & 53 \\
\hline Total & $\mathbf{1 4 0}$ & $\mathbf{1 0 0}$ & $\mathbf{8 0}$ & $\mathbf{1 0 0}$ & $\mathbf{1 5 0}$ & $\mathbf{1 0 0}$ \\
\hline
\end{tabular}

Table 4 above shows that most respondents indicated that most female teachers should be promoted to the post of teacher-in-charge of infant classes $(53 \%)$; followed by those who indicated that they should be promoted to deputy headship posts (29\%); $21 \%$ stated that they should be promoted to the post of headship; and a paltry $7 \%$ indicated that they should be promoted to posts of district education officer.

Table5. Responses to the statement: "Female heads are more autocratic than males" $(N=150)$

\begin{tabular}{|l|l|l|l|l|l|l|}
\hline Category of responses & Male & Female & \multicolumn{2}{l|}{ Totals } \\
\hline & F & \% & F & \% & F & \% \\
\hline Strongly Agree & 33 & 47 & 44 & 28 & 110 & 37 \\
Agree & 18 & 26 & 42 & 26 & 78 & 26 \\
Disagree & 12 & 17 & 34 & 21 & 58 & 19 \\
Strongly Disagree & 6 & 9 & 40 & 25 & 52 & 18 \\
Not sure & 1 & 1 & 0 & 0 & 2 & 0 \\
\hline Total & $\mathbf{7 0}$ & $\mathbf{1 0 0}$ & $\mathbf{8 0}$ & $\mathbf{1 0 0}$ & $\mathbf{3 0 0}$ & $\mathbf{1 0 0}$ \\
\hline
\end{tabular}


Information on table 5 above shows that the majority of respondents indicated that female heads were more autocratic than their male counterparts $(63 \%)$. Of these males were more vigorous as they represented $(73 \%)$ and females were $(54 \%)$. Those who thought that females were not autocratic constituted a total of $37 \%$ with females $(46 \%)$ being more on the side of their female colleagues. Only $26 \%$ of the males stated that female heads were not more autocratic than their male counterparts.

Table6. Responses to the question: Are women in leadership positions in schools promoted through favoritism $(N=300)$

\begin{tabular}{|l|l|l|l|l|l|l|}
\hline Category of responses & \multicolumn{2}{|l|}{ Male } & Female & \multicolumn{2}{l|}{ Totals } \\
\hline & F & \% & F & \% & F & \% \\
\hline Strongly Agree & 124 & 89 & 104 & 65 & 228 & 76 \\
Disagree & 14 & 10 & 44 & 28 & 58 & 19 \\
Not sure & 2 & 1 & 12 & 7 & 14 & 5 \\
\hline Total & $\mathbf{7 0}$ & $\mathbf{1 0 0}$ & $\mathbf{8 0}$ & $\mathbf{1 0 0}$ & $\mathbf{3 0 0}$ & $\mathbf{1 0 0}$ \\
\hline
\end{tabular}

The above information reveals that the majority of respondents indicated that most women who are in leadership positions in schools were promoted through favoritism. These constituted $76 \%$ of the respondents. Only $19 \%$ believed that women in promotion posts were promoted on merit and 5\% were not sure. More males agreed with the statement (89\%) compared to $65 \%$ of the female respondents.

The questionnaire had two open-ended questions which bolstered responses from the closed-ended questions. The first question wanted to find out from the respondents what they thought were the advantages of promoting female teachers. A number of responses were put forward by the respondents. The most common ones are listed in order of popularity below:

- They make good role models for the girl child $-90 \%$.

- They were less aggressive to teachers than men $-88 \%$.

- They were not as prone to corrupt activities like embezzlement of public funds, abuse of teachers and children like their male counterparts $-82 \%$.

- They don't absent themselves from work like men $-78 \%$.

The second question wanted to find out from the respondents why they thought women should not be promoted to positions of leadership. The following responses were captured in order of popularity:

- Women are naturally weak to lead organisations $-94 \%$.

- Women are only concerned about their family lives $-87 \%$.

- Women rely too much on gossip and the grapevine $-83 \%$.

- Women teachers want to work in comfortable environments and yet some if not most promotion posts are in not so good areas $-75 \%$.

\section{DISCUSSION}

Most teachers from this study believe that female teachers should be confined to the low post of teacher-in-charge of infant classes. Infant classes cater for the young children and this could be associated with the role of women in the home of looking after small children. This finding tallies with observations by Ozigi (2004) who states that sex roles, stereotyping and career mapping of women emerge as strong barriers to female advancement into positions which have traditionally been associated with men, particularly management positions.

Data also reveals that respondents felt that female heads were more autocratic than male ones. More males than females stated that female heads were more autocratic than male heads. This could be understandable because most people associate women with being tender, caring and tolerant. If women then act according to the male definition of a leader (being aggressive, achievement oriented, self-confident, forceful or competitive) she is condemned as being unfeminine (Smyth, 2012).

Information also show that most respondents thought that most women in leadership positions were not promoted on merit; but rather, through some kind of favour or dubious criteria. This could be as a 
result of the affirmative action that the government has taken to uplift women teachers. As Makombe (2008) postulates, through the affirmative policy, the education system introduced the women advancement system in which more women were deliberately promoted to higher posts even with lesser academic and professional qualifications and experience than men. This positive discrimination has created negative attitudes towards the beneficiaries of the system.

Data also reveal that in spite of the negative attitudes towards promotion of women, teachers still believe that there is need to have women in promotion posts so that they may be role models for the girl children. It is therefore important that women are visible as leaders to encourage the young girls with their education. As Smyth (2012) argues, young girls become motivated when they see women taking charge of other people as this fights against the stereotypes that always show women being led by men.

The respondents also indicated that women leaders were not as prone to corrupt activities as their male counterparts. This perhaps could be due to the fact that there are currently more men in leadership positions and this increases the probability of men in positions of authority to be reported in cases of corruption and other vices than women. This finding tallies with observations by Robbins (2011) who states that women were more democratic, they encouraged participation, did not sexually abuse children and teachers alike as most men would generally do when occupying a similar position.

Data also reveal that respondents felt that women leaders were weak, concerned with their families and relied heavily on gossip to take decisions. They also wanted comfort and did not want to sacrifice, that is why they wanted to be deployed in good schools. This reduced their chances of getting promoted as most vacancies were in areas with little comfort. As Rammer and Davies (2012) observe, women cannot handle responsibility because they are not natural leaders, they lack confidence in work relate competition.

\section{Conclusions}

Given the background of the above findings, the researcher makes the following conclusions:

- Both theoretical and empirical data in this study converge on the fact that most males have negative attitudes towards women in leadership positions.

- Most teachers believe that women should be promoted into lower level posts like the teacher-incharge of infant classes post.

- Women heads or leaders are seen to be more autocratic than male ones.

- Women were seen as being not capable of gaining promotion through merit, but rather rise through favoritism.

- Women should be promoted in order to provide role models for the girl children.

- Women leaders were not prone to corruption.

- Women leaders were weak, concerned with their families and relied on gossip.

6. RECOMMENDATIONS

In light of the findings of this study, the researcher would like to make some recommendations:

- The Ministry of Education should promote women on merit and avoid affirmative action as this builds negative perceptions towards women leaders.

- The Government and various teacher organisations should sensitise male teachers about the importance of having women leaders in the education system as most males have a low opinion over women leaders.

- All administrators, especially the newly promoted ones, should be inducted on leadership (particularly the women leaders) in order to guide them on best practices on leadership so that negative attitudes towards their leadership styles may be minimized.

\section{REFERENCES}

[1] Al-Khalifa, E. (2008). Management of halves: Women teaches and school management in managing change in education. London, Panter Publishers. 
Perceptions of Teachers on the Promotion of Women into Leadership Positions in the Ministry of Education in Eswatini: the Case of Manzini Region

[2] Best, J. W. (2013). Articulation education and cooperative planning. Florida, Prochaim-Nova University.

[3] Chivore, B. R. S. (2005). Educational administration and management; A methodological handbook for primary school heads in Zimbabwe. Harare, University of Zimbabwe.

[4] Cohen, L. and Manion, L. (2009). Research methods in education. London, Crown Helen.

[5] Culligan, A. (2012). Gender equality in religion. Washington, UNESCO.

[6] Davies, L. (2012). Gender and the management of education in Third World Countries in comparative education. Paris, Polity Press.

[7] Evetts, J. (2009). Gender and secondary leadership. London, Longman.

[8] Gaidzanwa, R. (2010). Images of women. Harare, College Press Limited.

[9] Johnson, S. M. (2010). Teachers at work. Boston,Basic Books.

[10] Lawson, W. and Lovell, S. (2010). Understanding research in education. London, University of London Press Ltd.

[11] Luke, C. and Gore, J. (2013). Feminism and critical pedagogy. London, Routledge Chapman and Hall Incl.

[12] Madziyire, N. C. (2010). Supervision of educational personnel in Zimbabwe. Harare, Zimbabwe Open University.

[13] Makombe, B. (2008). Educational leadership and supervision. Harare, Longman.

[14] Makoni, R. D. (2009). Supervision in schools. Harare, ZPH.

[15] Ozigi, j. (2004). Women in educational management. Buckingham, Routledge.

[16] Rammer, M. and Davies, J. E. (2008). How women leaders fare in management. New York, MacMillan.

[17] Robbins, T. (2011). Gender differences in comics. Visual Narrative, 4(3): 15-22.

[18] Shakeshaft, A. (2006). The female world of administrators. New York,Harper and Row.

[19] Smyth, J. (2012). Critical perspective on educational leadership. Basingstoke, Taylor and Francis Printers.

Citation: Wilard Nyathi, "Perceptions of Teachers on the Promotion of Women into Leadership Positions in the Ministry of Education in Eswatini: The Case of Manzini Region" International Journal of Humanities Social Sciences and Education (IJHSSE), vol 8, no. 4, 2021, pp. 01-07. doi: https://doi.org/10.20431/23490381.0804001

Copyright: () 2021 Authors. This is an open-access article distributed under the terms of the Creative Commons Attribution License, which permits unrestricted use, distribution, and reproduction in any medium, provided the original author and source are credited. 